\title{
Sugestões para a Contribuição de Juizes e Advogados à Reconstrução da Nacionalidade*
}

\author{
Fábio Konder Comparato \\ Professor Titular de Direito Comercial na Faculdade \\ de Direito da Universidade de São Paulo.
}

\section{Egrégio Conselho:}

Mais uma comemoração do 11 de agosto parece ocasião oportuna para se aprofundar a reflexão sobre a função social dos profissionais do Direito em nossos dias.

Este Egrégio Conselho, mercê da atuação desasombrada de seus membros, nas últimas gestões, granjeou algo de precioso, que outras instituições ou grupos, no poder há muitos anos, têm perdido: o respeito do povo brasileiro.

Importa, agora, antes de tudo, verificar como lançar mão desse capital invejável de autoridade moral, para tomar as decisões adequadas no momento oportuno. Sirvam, portanto, as reflexões que passo a expor como modesta contribuição para tanto.

Desponta em toda parte, a necessidade de uma revisão crítica da contraposição entre público e privado, tal como vigora, tradicionalmente, em nossa civilização.

De um lado, toma-se consciência de que a própria idéia de uma oposição de noções e, mais do que isso, de esferas de vida e atividades, aí, não existiu em todas as civilizações, mas parece, antes, uma característica do mundo greco-latino. É na cidade grega da época clássica, que se observa uma estrita separação entre a vida pública - onde plenamente se realiza a personalidade humana - e a vida privada, que apresenta

Alocução ao Conselho Federal da Ordem dos Advogados do Brasil, em 11 de agosto de 1979, aniversário de fundação dos cursos jurídicos no País. 
sempre um caráter de privação de realizações ou possibilidades. Por outro lado, é no direito romano que surge a tradicional dicotomia direito público - direito privado, que FRITZ ScHULz apresentou como um dos exemplos frisantes do princípio de isolamento, próprio do sistema jurídico daquele povo.

Note-se, no entanto, que essa oposição de noções tinha um sentido bem diverso do que ora conhecemos, pois o qualificativo "público", longe de se referir ao Estado, como ocorre hoje, designava o povo em geral ou a nação. $O$ vocábulo latino significava, originalmente, o que dizia respeito ao populus Romanus. Houve, sem dúvida, uma transposição de sentidos ao se traduzir a famosa sentença de UlPIANo, colocada no pórtico do Digesto (publicum ius est quod ad statum rei Romanae spectat) como se referindo ao Estado, enquanto organização institucionalizada do Poder; e não ao povo romano, como sociedade individuada. Aliás, a noção moderna de Estado era totalmente desconhecida dos romanos, que não tinham nem mesmo vocábulo adequado para expressá-la. 0 que houve, isto sim, é que 0 princípio de centralização política e administrativa em Roma, verdadeiro axioma no dizer de MoMmsEN, conduziu, muito naturalmente, os espíritos modernos a essa assimilação facilmente enganosa entre público e estatal, na leitura das fontes.

No mundo clássico, entretanto, público opõe-se a privado, na justa medida em que o comum se contrapõe ao próprio. Portanto, público é o que é de todos, e não o que pertence em propriedade ao Estado ou ao particular.

A grande revolução moderna, nesse particular, consistiu na progressiva absorção do comum pelo estatal. TocQUEVILLE já o denunciara há quase cento e cinqüenta anos. Ao analisar, alguns anos depois, o golpe de Estado de Luis Napoleão Bonaparte, MARX veio confirmar esse diagnóstico, numa amarga prefiguração do que o Estado comunista, que invoca a sua doutrina, desenvolveria ao máximo em nosso século. Observou, então, que o mecanismo estatal, complexo e artificial, constituiu-se na Europa à época da monarquia absoluta, com o declínio do feudalismo, que ela ajudara a derrubar. Dentro desse aparelho estatal, em perpétuo crescimento, o trabalho foi dividido e centralizado como numa fábrica. À medida que a divisão do trabalho criava novos grupos de interesse no seio da sociedade civil, desenvolviam-se novos materiais para a administração estatal. Assim, "cada interesse comum foi imediatamente destacado da sociedade, oposto a ela a título de interesse superior, geral, subtraído à iniciativa 
dos membros da sociedade, transformado em objeto de atividade governamental, desde a ponte, o prédio da escola e a propriedade comunal do menor vilarejo até as ferrovias, os bens nacionais e as universidades." E concluía: "Todas as revoluções políticas só fizeram aperfeiçoar essa máquina, em lugar de quebrá-la. Os partidos que lutaram pelo poder consideraram, cada um por sua vez, a conquista desse imenso edifício do Estado como a principal presa do vencedor."

$\mathrm{Na}$ formação da sociedade e do Estado brasileiros - o segundo precedendo à primeira, numa inversão histórica extraordinária - observa-se com grande clareza esse fenômeno de esmagamento da esfera do comunitário, pela pressão combinada do estatal e do particular. As suas origens remontam ao longo processo de apropriações, desenvolvido pelos colonizadores, e que teve início desde antes do descobrimento, com a precoce experiência de capitalismo de Estado que a monarquia portuguesa, antes de qualquer outro país europeu, instituiu a partir da dinastia de Aviz.

No segundo sécuĩo da colonização, o Padre SImÃo DE VASCONCELOS escrevia que "nenhum homem nesta terra é repúblico, nem vela ou trata do bem comum, senão cada um do bem particular. Pois o que é fontes, pontes, caminhos e outras cousas públicas, é uma piedade, porque, atendo-se uns aos outros, nenhum as faz ainda que bebam água suja, e se molhem ao passar os rios e se orvalhem ao passar os caminhos." (História da Provincia de Santa Cruz). Não se pode dizer que, trezentos anos após, esse julgamento, aplicado às condições modernas de vida, tenha perdido atualidade. Não foram, certamente, o formidável reforço do poder estatal e a sua decisiva intervenção na vida econômica que ajudaram a desenvolver no brasileiro esse comportamento de repúblico, reclamado pelo velho cronista.

E bem verdade que a par dessa ausência de espírito comunitário e de organização de uma esfera do social não submetida à imposição do Estado, não existe sempre ao longo de nossa História, uma perfeita distinção entre o público e o privado mas, freqüentemente, inteira confusão entre ambos. Em monografia recente, na qual expôs interessante interpretação da estrutura social brasileira, à luz de sua evolução histórica, uma professora da Universidade de São Paulo pôde apontar, pela análise sistemática das atas da Câmara Municipal de Guaratinguetá, no século passado, grande número de casos em que recursos particulares subsidiavam obras públicas, ou em que dinheiros públicos entravam, promiscuamente, no giro de 
patrimônios particulares, sem que essa situação de indistinção aberrasse dos padrões normais de conduta da coletividade. Em outros casos, improvisavam-se forças policiais com os lavradores disponíveis, ou atribuiam-se funções de delegado de p.olícia a meros amadores, atuando plenamente, portanto, o instituto do funcionário de fato. (MARIA Sylvia DE CARvalHo Franco, Homens Livres na Ordem Escravocrata).

Dir-se-á que tais situações eram simples manifestações daquele poder privado, que teria prevalecido nos primórdios da colonização, como reflexo da impotência do Poder Público. Mas o fato é que o inverso também se manifestava, e largamente, com o Estado multiplicando os estancos e distribuindo cargos a granel, sem nenhuma correspondência com as necessidades do serviço público, como testemunharam, com surpresa, vários viajantes estrangeiros.

Tem-se, mesmo, a impressão de que essa confusão entre a esfera pública e a privada não está ligada ao grau de desenvolvimento sócio-econômico, mas resulta, quase que necessariamente, da identidade de natureza de ambas as situações, igualmente fundadas na apropriação de bens.

Prova disso é a verificação da atual superação de fronteiras entre direito público e direito privado nos mais adiantados países do mundo capitalista.

Assim é que a era das sociedades por ações e a vulgarização dos títulos de crédito introduziram técnicas típicas do direito público na vida privada quotidiana.

A sociedade anônima, favorecendo a concentração do poder econômico e a criação de situações de dominação sobre vastas camadas populacionais, suscitou a necessidade de se adaptar o emprego, contra os abusos do poder empresarial, de remédios jurídicos análogos aos que se criaram, no passado, para a proteção do particular frente ao Estado, como a responsabilidade pelo desvio de controle acionário, ou por abuso de poder econômico nos mercados. Por outro lado, essa dominação empresarial, ao mesmo tempo em que assusta pelo seu potencial de esmagamento, apresenta-se também, muitas vezes, sob a aparência sedutora da beneficência pública, organizando recreações e a assistência social para as famílias de seus dependentes, patrocinando certames artísticos e criando fundações culturais para o grande público. A esse respeito, já se falou com razão numa refeudalização da economia.

Os títulos de crédito, a seu turno, introduziram nas relações de troca entre particulares, por atos de autonomia pri- 
vada - isto é, negócios jurídicos - técricas de pagamento e de crédito até então privativas tão só da moeda e dos papéis públicos.

Em sentido oposto, o direito público se privatiza. Exemplo disso são o procedimento contratual para a realização dos planos econômicos nacionais, a introdução da política de estímulos e incentivos, completando as clássicas autorizações e proibições administrativas; e a adoção da técnica dos seguros privados para a socialização dos riscos coletivos mais importantes, seja por meio dos seguros obrigatórios, seja por via do resseguro obrigatório controlado pelo Estado, seja, ainda, pela assunção direta do risco por este ou, sobretudo, pela generalização da previdência social.

Assim, o direito público adota os procedimentos e instituições tradicionais do direito privado, consistentes na tríplice função de repartir, assistir e estimular.

Tudo isso está a indicar a necessidade de uma reorganização institucional que favoreça a criação dessa esfera de vida comunitária, em que os homens possam, como disse Martin BUBER, experimentar, deliberar e administrar em conjunto as coisas reais de sua vida em comum, organizando vizinhanças autênticas e associações efetivas de trabalho.

Penso que aos profissionais do Direito, valendo-se do inestimável tesouro de uma multi-secular experiência de solução de problemas humanos, caberá, naturalmente, a magna pars nessa tarefa de reconstrução societária. Para tanto, importa sobretudo atuar em permanente contato com os problemas concretos do povo, e não procurar esquematizar a vida social, more geometrico. E, de fato, a exigência de "concreção" constitui uma das características do pensamento jurídico contemporâneo, em todos os setores. Dela se podem extrair conclusões importantes quanto à via política (em sentido amplo) a ser seguida. Temos, assim, que a abstração geométrica foi a nota dominante do pensamento setecentista europeu, produzindo, no campo da ciência jurídica, a Escola do Direito Natural, em economia o liberalismo e, em matéria constitucional o privilegiamento do Legislativo, como Poder encarregado de formular as normas gerais. A reação antiliberal, a partir do Welfare State e das revoluções comunistas, buscou sem dúvida o concreto, mas sempre por meios autoritários; de onde o reforço inevitável do Executivo, poder heterônomo em relação à sociedade, como visualizara MoNTESQUIEU. Trata-se, agora, de revalorizar o concreto por meio da composição dialógica de 
conflitos, o que supõe naturalmente, o reforço da autoridade do Judiciário.

Ora, a revalorização, por via judicial, da esfera do comunitário, frente ao estatal e ao particular, passa, necessariamente, por uma adequada proteção em juízo dos chamados "interesses difusos" ou, como preferem denominar os alemães, "interesses gerais amplamente conflitivos" (breitgestreute Allgemeininteressen), tais como o equilíbrio ecológico, a beleza paisagística, o valor histórico ou arqueológico de determinado sítio, a saúde coletiva, a incolumidade da massa de consumidores. Trata-se, como se vê, de bens ou interesses que não se ligam a pessoas determinadas, mas a toda a coletividade ou a grupos de contornos indefinidos. Por isso mesmo, são insuscetíveis de apropriação, seja pelos particulares, seja pelo Estado.

Daí a inevitável perplexidade que se coloca, no campo processual, quanto às exigências de legitimidade para agir.

De acordo com a regra clássica pas d'intérêt pas d'action, o particular só estaria legitimado a agir em juízo para a defesa de interesse próprio. Como os interesses difusos ultrapassam, de muito, a esfera individual ou particular, o indivíduo lesado, diretamente, pela violação de um desses bens coletivos não teria, em concreto, nenhum estímulo para atuar judicialmente contra o violador, pela reduzida dimensão econômica desse dano ao patrimônio próprio dele, autor. Na mesma medida, para o violador - em geral uma grande empresa ou uma entidade pública - o risco econômico da responsabilidade de reparação de um dano individual seria desprezível.

De seu turno, o Ministério Público, tal como se acha enfeudado no aparelho estatal, tampouco é levado a se movimentar na defesa de interesses que não são próprios do Estado. E o Executivo, por intermédio de seus agentes administrativos, nem sempre se faz atuante para punir, na hipótese de existirem precisas normas administrativas que tenham sido violadas; quando não se deixa levar pelo esprit du siècle produtivista, de concerto ou não com os empresários, tudo sacrificando pelo aumento do P.N.B.

Encontramo-nos, pois, como bem disse um autor italiano diante de interesses em busca de um autor, numa situação dramaticamente pirandelliana.

Toda essa temática tem sido amplamente versada no estrangeiro, e mereceu entre nós de JosÉ CARLOs BARBosa Moreira, primoroso estudo em homenagem a ENRICo TUllio Liebman (A Ação Popular do Direito Brasileiro como Instru- 
mento de Tutela Jurisdicional dos Chamados "Interesses Difusos" publicado em Temas de Direito Processual, São Paulo, ed. Saraiva, 1977). Nesse estudo, aquele distinto processualista observou que a ação popular, consagrada no art. 153, $\S 31$ da Constituição como garantia de direitos individuais, e disciplinada pela Lei n. ${ }^{\circ} 4.717$, de 1965 , atende em grande parte a esse objetivo de proteção aos interesses coletivos.

Meu intento, agora, no entanto, é salientar as insuficiências desse remédio processual para a plena realização desse objetivo, tendo em vista a sua origem estritamente publicista.

Em primeiro lugar, quanto à qualificação do réu. $O$ texto constitucional fala em "ação que visa a anular atos lesivos ao patrimônio de entidades públicas". Se bem que a Lei n. ${ }^{\circ} 4.717$ haja ampliado ao máximo a abrangência da expressão "entidades públicas", o fato é que não se pode estender a legitimidade passiva ad causam também a sociedades privadas, sem participação estatal, ou a entidades estrangeiras ou sob controle estrangeiro por exemplo. Ora, como sabido, grande parte dos atos violadores do interesse do consumidor provêm dessas últimas, e não de entidades públicas. Nem se pode pretender que nessa violação sistemática dos interesses coletivos o único responsável seja o Estado. Por outro lado, mesmo considerando, como fez a Lei n. ${ }^{\circ} 4.717$, que o patrimônio público inclui os bens e direitos de valor econômico, artístico, estético ou histórico, não se há de admitir que os interesses gerais da coletividade possam, de algum modo, ser assimilados a interesses estatais propriamente ditos, consolidando destarte a confusão de esferas de vida que se tenta agora, penosamente, dissipar.

Do lado do autor, correlatamente, a ação popular para a proteção da mais ampla gama de interesses coletivos deveria caber não apenas a qualquer cidadão, mas também a qualquer do povo - seja ou não titular de direitos políticos - e também a associações reconhecidas de utilidade pública. É que estamos, aí, não no campo da representação de vontades do direito privado clássico, mas no terreno da representação de interesses, cuja invocação, pelo autor, não precisa vir acompanhada da prova de sua titulação em pessoas certas e qualificadas. De resto, mesmo no campo do direito privado, a instituição das fundações constitui belo exemplo dessa legitimidade para representar interesses e não vontades. $\mathrm{E}$ de qualquer modo, a partir do momento em que estão em causa não indivíduos mas grupos inteiros ou categorias de pessoas, as noções de vontade, intenção e mesmo de culpa perdem todo sentido. 
No que tange ao risco da demanda, a Lei $n 0^{\circ} 4.717$ introduziu disposição inovadora, sem dúvida inspirada no processo penal, ao determinar que os efeitos da coisa julgada se estabeleçam secundum eventum litis, isto é, aproveitando a todos os sujeitos que se encontrem na mesma categoria que o autor da demanda, se for julgada procedente; mas sem impedir novo ajuizamento da lide, ainda que pelo mesmo autor, se improcedente o pedido inicial por insuficiência de provas. Conviria, porém, no tocante ao outro lado do risco processual, referente ao custeio da causa e aos ônus da sucumbência, estabelecer o regime de gratuidade das custas e admitir também, de acordo com o precedente em boa hora aberto pela nova lei de sociedades por ações (art. 246, § $2^{\circ}$ ), que em caso de julgamento favorável à pretensão do autor, tenha ele direito a receber não apenas o reembolso das despesas processuais e a verba honorária, como ainda um prêmio adicional, arbitrado pelo juiz. Com efeito, a justiça gratuita, em qualquer hipótese, e o prêmio em caso de vitória processual se justificam, cabalmente, como estímulos necessários à defesa de interesses coletivos, por particulares que assumem, com isto, as funções de autêntico substituto do Ministério Público ou, como dizem os norte-americanos, private attorney general.

Resta, por fim, a delicada questão da causa de pedir. Basta, para a anulação ou decretação da nulidade do ato, que ele seja reconhecido como lesivo, ou deve-se provar, também, a sua ilegalidade? A Lei n. ${ }^{\circ} 4.717$, redigida por mão de mestre, procurou, sem dúvida, alargar o conceito de nulidade do ato administrativo, nele incluindo não só a incompetência, o vício de forma e a ilicitude do objeto, como também a inexistência do motivo expresso e o desvio de finalidade (art. $2 .^{\circ}$, parágrafo único). Mas não parece haver eliminado, como já se pretendeu, o requisito da ilegalidade. Aliás, o art. $3 .^{\circ}$ daquele diploma legal, ao tratar dos atos anuláveis, não deixa de assinalar que eles serão apreciados, para a determinação de seu caráter vicioso, "segundo as prescrições legais" Como se poderia, na verdade, afastar a questão da legalidade, quando o texto constitucional, tradicionalmente, fala em nulidade e anulabilidade? Tais categorias não implicam, como é óbvio, um juízo de legalidade?

Poder-se-ia reformular, de modo mais genérico, a questão proposta, indagando se, e até onde, o ato administrativo discricionário é suscetível de censura judicial. Com efeito, segundo a interpretação tradicional do princípio da separação de Pode- 
res, a Administração Pública é soberana na apreciação da oportunidade e a conveniência dos seus atos não vinculados. Mas até que ponto a oportunidade e a conveniência do ato administrativo não caem sob o crivo judicial, quando da prática desse ato, ou de sua omissão, resulta grave lesão aos interesses coletivos? O ato discricionário, como disse um autor suíço, é o verdadeiro cavalo de Tróia do Direito Administrativo no seio de um Estado de Direito. E não é por outra razão que o Conselho de Estado francês, após reconhecer, pelo acórdão Grazietti do início do século, que já não existem atos inteiramente discricionários em Direito Administrativo, vem reduzindo paulatinamente, desde então, a zona da discricionariedade, fundando-se no princípio de que, onde a lei é omissa, compete ao juiz criar a regra de direito; e ele o faz, apreciando in concreto a oportunidade e conveniência da ação administrativa, como se fora o próprio Poder responsável pela prática do ato.

Conviria, pois, aí, que a lei reconhecesse explicitamente o poder judicial de impedir ou desconstituir quaisquer atos lesivos do interesse coletivo, não autorizados, de modo expresso e inequívoco, pela lei.

Mas não será isto atribuir poderes administrativos e quase-legislativos ao Judiciário?

Efetivamente, nos Estados Unidos, o exercício dessa ampla função regulatória pelos juízes tem ocorrido em hipóteses sempre mais numerosas. Tratando-se de aplicar o princípio da não-discriminação racial nas escolas, deve o juiz não somente dizer se um decreto municipal que determina sejam as crianças matriculadas na escola pública do seu bairro importa em discriminação de fato, mas também elaborar um programa de transporte coletivo de escolares de um local para outro, atendendo a questões práticas de custeio e de horário. Cuidando-se do princípio de igualdade de oportunidades na educação, e decidindo o magistrado que a desigualdade na distribuição de verbas públicas entre as diferentes escolas implica um desigual nível de ensino, compete-lhe assentar a reelaboração do orçamento público para superar aquelas desigualdades. Tratando-se de impor a norma constitucional de que não haverá penas cruéis e inabituais, o Judiciário vê-se diante da perspectiva de dever organizar toda uma programação de garantias de bem-estar mínimo para os detentos, desde a quantidade e a potência de lâmpadas a serem instaladas nas celas das prisões até a periodicidade da lavagem das roupas ou da desinfecção dos sanitários. 
No exercício dessas funções, muito embora os autores ianques sublinhem o seu caráter extraordinário em relação à concepção tradicional do Poder Judiciário, é preciso reconhecer a influência decisiva da equity, que marcou tão fundamente o sistema jurídico anglo-americano. Pois, de fato, decidindo in equity e não in law, o antigo chanceler britânico, tal como o pretor romano, não se via jungido por normas legais estritas nem pela força de precedentes, mas atuava como verdadeiro titular de um poder administrativo e mesmo legislativo. Não foi assim, aliás, que de 1870 até 1933, ano em que o Congresso norte-americano editou a primeira lei específica sobre a reorganização de companhias ferroviárias, os juízes norte-americanos promoveram, unicamente com base na eqüidade, mais de 1.000 soluções desse tipo?

Analisando essa espécie de processo judicial, que denominou public law litigation o Professor ABRAM CHAYES, da Universidade de Harvard, assim resumiu as suas características:

1. o escopo da demanda não é exógeno, mas definido primacialmente pelo juiz e as partes;

2. o contraditório não se estabelece de forma rigidamente bilateral, mas difusa;

3. a perquirição dos fatos não é histórica, de modo a submetê-los à lei existente, mas em previsão do direito novo a ser criado;

4. a solução judicial não se reporta a fatos passados, nem se limita às partes na causa, mas visa ao futuro, de modo flexível e largo, com importantes conseqüências para muitas pessoas, inclusive ausentes à relação processual;

5. a decisão não é imposta, mas negociada;

6. a sentença não esgota a jurisdição no caso, mas implica a participação contínua do juiz na realização do programa por ela traçado;

7 o juiz não é passivo, no sentido de a sua função limitar-se a dizer o direito aplicável à espécie; ele deve estimar os fatos e organizar o procedimento, para facilitar o encontro de uma solução justa e viável;

8. objeto da demanda não é uma lide entre partes sobre direitos próprios, mas uma reclamação sobre ações ou omissões políticas. 
No direito brasileiro, só temos um processo judicial com essas características: é o dos dissídios coletivos de trabalho, previstos no art. $142, \S 10^{\circ}$ da Constituição. Não é preciso salientar a sua importância crescente nos dias que correm, como remédio para o desbloqueamento da ação governamental e a parálise de um Legislativo inautêntico, em período de crise econômica.

Na verdade, a generalização desse procedimento se impõe, como instrumento eficaz de constituição da esfera do social, entre o privado e o público. 0 principal fundamento para tanto já existe em nosso direito positivo: são as disposições ditas programáticas da Constituição.

Com efeito, a doutrina jurídica nacional, embora rejeitando a tese de que essas normas constitucionais seriam tecnicamente ineficazes, assentou, no entanto, o princípio de que tal eficácia seria sempre limitada ou mediata, ou, em outras palavras, que as disposições preceptivas da Constituição criaram "direito subjetivo em seu aspecto negativo, não o gerando sob o ângulo positivo" como disse uma jurista. Em termos práticos, significa isto que o efeito jurídico das normas constitucionais programáticas só se manifestaria por ocasião de uma eventual disputa a respeito da compatibilidade, em relação a elas, de normas legais que contrariassem o sentido do preceito ou programa declarado na Constituição. Convenhamos que é pouco, ridiculamente pouco. Há casos, até, em que essa possibilidade de "criação de direito subjetivo em seu aspecto negativo" é pura vue d'esprit, pois lei alguma seria editada contrariando o preceito constitucional; o legislador ordinário simplesmente se omite.

A via do procedimento judicial de interesse coletivo, estabelecendo normas e fixando as condições para a correção de uma injustiça generalizada, é a verdadeira solução para a recusa de aplicação, pelo Legislativo e o Executivo, dos princípios solenemente proclamados na Constituição da República. Quando esta declara que "a ordem econômica e social tem por fim realizar o desenvolvimento nacional e a justiça social, com base no princípio da "expansão das oportunidades de emprego produtivo" (art. 160, VI), está ipso facto invalidando políticas e programas governamentais que geram o desemprego, como custo inabsorvido da incapacidade de planejamento ou do deliberado propósito de favorecer programas de redução da mão-de-obra nas empresas. Quando se lê que "a Constituição assegura aos trabalhadores "integração na vida e no desenvolvimento da empresa, com participação nos lucros e excepcional- 
mente, na gestão" (art. 165, v), não se pode cancelar todo efeito jurídico ao princípio, com fundamento na parte da norma - "segundo for estabelecido em lei" - ; pois não é esta que assegura tal direito e, sim, a própria Constituição; a menos que se queira subordiná-la à lei, ou dar ao Congresso, pela sua simples inação, o poder de revogar, tacitamente, dispositivos constitucionais. Quando a educação é declarada, peremptoriamente, "direito de todos e dever do Estado" (art. 176), pode o Judiciário recusar-se a condenar o Poder Público a dar educação à legião de jovens brasileiros sem escola, sob o pretexto de que se trata de uma questão de natureza política, que não compete aos juízes resolver?

Escrevendo em momento de grande agitação política, o preclaro PEDRo LESSA advertia que o Poder Judiciário "diferencia-se dos outros dois poderes constitucionais pela natureza da função por ele exercida, ratione muneris, e não pela matéria, ratione materiae. Não há assuntos que por sua natureza sejam de ordem legislativa, ou de ordem administrativa, ou judiciária. Uma só matéria pode ser legislativa, executiva e judicial" (Do Poder Judiciário, Rio, 1915, p. 2).

De fato, o princípio da distinção dos Poderes não implica o estabelecimento de funções exclusivas, mas a distribuição de tarefas específicas entre órgãos diferentes, no Estado. De onde a natural colaboração entre eles. Já se observou, aliás, que a idéia de uma separação de poderes - vulgarizada na tradição francesa, mas não na norte-americana - trai o pensamento de MONTESQUIEU, que empregou reiteradamente a expressão "distribuição de poderes", só falando em separação uma única vez, sintomaticamente, a respeito do Judiciário. Ces trois puissances, escreveu ele, devraient former un repos ou une inaction. Mais comme, par le mouvement nécessaire des choses, elles sont contraintes d'aller, elles seront forcées d'aller de concert (De l'Esprit des Lois, livro XI, cap. VI).

O Judiciário, tal como os demais Poderes, pode tanto estatuir quanto impedir. $O$ poder de estatuir, como o definiu MONTESQUIEU, consiste em determinar as matérias de sua própria competência, bem como corrigir o determinado por outrem. O impedimento é o poder de bloquear as decisões de outros órgãos, nos limites da organização política. O Judiciário impede, por exemplo, quando julga inconstitucional uma norma emanada do Legislativo. Trata-se agora, de reconhecer, amplamente, o poder judicial de estatuir em termos gerais e para o futuro, diante de um conflito de interesses coletivos. É, de resto, o que vem fazendo a nossa Justiça do Trabalho, 
nos processos de dissídio coletivo de natureza econômica. Assim agindo, o Judiciário presta a sua colaboração indispensável ao progresso social, sem usurpar minimamente as atribuições do Legislativo, pois este, como bem salientara MONTESQUIEU, não é feito para tomar "resoluções ativas".

A objeção de que as normas constitucionais ditas programáticas careceriam, para serem eficazes; de complementação por lei do Congresso Nacional, sobre ser insustentável, como acima frisei, já foi rejeitada indiretamente, em matéria de dissídios coletivos de trabalho, pelo Supremo Tribunal Federal. Nesse caso, o próprio texto constitucional determina que a lei especifique as hipóteses em que as decisões judiciais podem estabelecer normas e condições de trabalho. Veio a Lei $n .^{\circ}$ 4.725, de 1965, e somente especificou — ainda em caráter absurdamente restritivo - como deveriam ser reajustados os salários. Pois a Justiça do Trabalho não se sentiu coartada, e com razão, por essa omissão legislativa, e passou a estabelecer, nos dissídios coletivos, outras normas e condições de trabalho, independentemente dos salários.

Resta a dificuldade de que, em nossa Constituição, somente nessa hipótese foi o Judiciário, explicitamente, autorizado a estatuir normas gerais, válidas e eficazes para toda uma categoria. Lembro, no entanto, que no regime constitucional norte-americano - de estrutura geral idêntica à do nosso - a Constituição não contém dispositivo algum dessa natureza; o que não impediu juízes e advogados de avançar, decididamente, nessa linha. Nem se diga que, lá, a equity justificaria o procedimento propter legem. Na verdade, ela é, tão-só, uma justificativa histórica, pois o sistema equitativo foi expressamente fundido no common law, para o qual, como não deixam de frisar os próprios juristas norte-americanos, a public law litigation é completa novidade.

Admitiria, no entanto, para dissipar escrúpulos tradicionalistas, que o assunto fosse regulado, entre nós, por lei ordinária, já que, como salientei, princípio algum constitucional a tanto se opõe.

\section{Egrégio Conselho:}

Se a reconstrução democrática da nacionalidade, após a aventura da segurança nacional, passa, como estou convicto, por uma organização autônoma da vida social, entre as fronteiras da ação do Estado e do interesse particular, ouso afir- 
mar que as idéias aqui expostas representam a tradução atual do dever deste Colendo Conselho de "defender a ordem jurídica e a Constituição da República, pugnar pela boa aplicação das leis e pela rápida administração da justiça e contribuir para o aparfeiçoamento das instituições jurídicas" (Lei n. ${ }^{\circ}$ 4.215 , art. 18, I).

Dispondo-se os advogados brasileiros, com generosidade e competência, a atuar desde logo nesse campo, estarão firmando, perante uma sociedade sempre mais descrente dos que a comandam, sua velha tradição de especialistas em humanidade. 